\title{
A comparative analysis of the future cost of electricity generation in OECD and non-OECD countries
}

\author{
Jason West ${ }^{1}$ \\ Griffith University
}

28 March 2011

\begin{abstract}
With the growth in liberalised electricity markets and the advent of climate change policy imposing a price on emissions, investment in the global future energy mix will be greatly dependent on the expected generation cost of alternate energy sources. The implicit capital, operating and fuel costs of major electricity generation technologies, including the cost of carbon dioxide emissions, are compared for developed and developing nations using a levelised cost of energy approach. This relatively simple analytical tool allows investors to directly compare alternative technologies which have different scales of operation and investment horizons on a stand-alone basis. The analysis demonstrates that fossil fuels will continue to remain competitive relative to nuclear, hydro and wind generation sources over the long term in OECD countries and highlights the large cost advantage of fossil fuel generation relative to renewable technologies in non-OECD nations. The study also shows that the price applied to carbon-dioxide emissions may need to significantly increase to induce behavioural change in power generation investment in the absence of direct regulation.
\end{abstract}

Key words: energy, investment

\section{INTRODUCTION}

Central to the development of the global energy mix is the expected future cost of alternative energy sources. Climate change policies imposed by governments are seeking ways to alter the energy mix away from fossil fuels but as this analysis shows, such responses must be carefully planned lest the true cost of long-term sustainable energy supply be biased towards less efficient energy sources. Excessive energy costs relative to regional benchmarks will undoubtedly translate into competitive disadvantages. Importantly the magnitude of the investment and social costs for a given energy source prevents dramatic changes to the energy mix midway through a development cycle. Often there is no turning back once the development pipeline is underway. For instance, generators in the US and Europe are experiencing difficulties in decommissioning baseload power plants that have an effective remaining life of 30 years, particularly in cases where most of the capital costs have yet to be recovered.

The composition of the electricity supply in developed nations over the 2011 to 2025 period will be influenced by a number of factors in the energy policy arena, most notably:

- policy settings for renewable energy;

- the cost and availability of different fuel sources (the costs of fuel will partly depend on the price signal for carbon dioxide);

- the cost of competing generation technologies;

- the extent to which alternative technologies are commercialised;

- societal attitudes towards alternative generation technologies, especially nuclear; and

\footnotetext{
${ }^{1}$ Department of Accounting, Finance and Economics, Griffith Business School, Nathan, QLD, Australia, 4111, +61 737354272 (w), email: j.west@ griffith.edu.au
} 
- the capacity of transmission and interconnection infrastructure as well as the regulatory framework.

The availability of low-cost energy for the major developing nations is critical to their economic growth. The likelihood of most developing nations setting stringent climate change policies to curb the growth in electricity generated using fossil fuels is low. Therefore the composition of the electricity supply in developing nations over the 2011 to 2025 period will be influenced by fewer climate change factors and focus on sourcing reliable, inexpensive and cost competitive energy.

The following analysis compares the costs of competing generation technologies including carbon dioxide costs over the long term, using the levelised cost of energy as a benchmarking tool. We deploy the levelised cost of energy approach because it is a relatively simple analytical tool to compare alternative technologies when different scales of operation, investment or operating time periods exist. The levelised cost can therefore be used to compare the cost of energy generated by a renewable power plant with that of a fossil fuel generating unit or other technology, despite gross differences in construction times, plant life, capital outlay and importantly the nationality of the generator. The calculation for the levelised cost in general terms is the ratio of the net present value of total life cycle costs of the project to the quantity of energy produced over the system life.

A variety of other approaches such as payback period, internal rate or return and net present value calculations are used in energy production studies and the shortcomings of each are well known. One capital budgeting approach methodology traditionally employed by utilities is known as the revenue requirements method (RRM) which is unique to the electricity generation industry. The RRM represents an expression of the costs of an investment where revenue requirements are defined as the expected revenues that will provide a minimum acceptable return to investors. Costs and revenues are equalised through regulation so that the present value of revenue requirements reflects future costs. Lind (1982) and Awerbuch (1996) criticise the RRM approach as it incorporates a number of restrictive strategic, operational and financial assumptions including perfect regulation and strict monopoly, equivalency of output independent of the supply technology employed, financial risks are similar for all technologies and guaranteed capital recovery for any capacity addition. The strict assumptions guiding the RRM approach do not allow for structural differences in energy regulation between developed and developing countries. In contrast the levelised cost of generation approach allows for direct comparisons in costs to be made which are aligned with the economic principles underlying energy production. Thus the levelised cost of generation is employed in this analysis to compare developed and developing countries' expected generation costs by type. Developed countries are assumed to be members of the Organisation for Economic Cooperation and Development (OECD) while developing nations are represented as non-OECD nations.

Levelised cost analysis has been conducted in a variety of contexts and countries such as Australia (CSIRO 2006), UK (Mott Macdonald 2010) and the US (California Energy Commission 2007) however no levelised cost analysis has been conducted to obtain a comparative view of global power generation to make direct comparisons between the expected levelised costs for electricity generation in OECD and non-OECD countries. This study seeks to address this gap in the literature.

\section{ENERGY INVESTMENTS}

Regardless of the motivation behind investing in alternative energy sources, a clear appraisal of the relative costs and benefits that arise from competing sources is required to inform decision 
makers. The major energy generators and private equity investors are likely to dominate investment in the evolving global energy mix, so long as they provide returns on investment commensurate with risk over the long term. Understanding the cost drivers of electricity generation is critical to assess these investment alternatives.

The liberalisation of the electricity markets in many developed countries has removed part of the regulatory risk shield where integrated monopolies can transfer costs and risks from investors to consumers and taxpayers. Investors now have additional risks to consider and manage. For example, generators are no longer guaranteed the ability to recover all costs from power consumers, nor is the future power price level guaranteed. Investors must internalise these risks which adds to the required rates of return. It also diminishes the time horizon of financiers seeking to fund investment and for investors to recover capital. Private investors' required real rates of return are likely to be similar to the discount rate used in this study however the time required to recover invested capital is generally much shorter than the average life of a generating unit. In contrast with the general trends in developed countries, electricity generators in developing countries experience varying degrees of government ownership, price regulation, transmission inefficiencies and technology incentives. While the levelised cost is not the only metric available for framing investment decisions, it is the most appropriate benchmark for comparing operating margins and capital costs across different generation types in countries at different stages of economic development.

There are some general features of electricity generation in both developed and developing countries. The demands on electricity supply infrastructure are growing, with increasingly distributed and variable sources of generation, including wind and solar power adding to the complexity of distribution. Electricity demand does not respond quickly to price changes when supply conditions change and there appears to be a lack of timely and diverse electricitygeneration investment, as well as a lack of significant investment in transmission interconnection. There is often public opposition to the location of new generation and transmission infrastructure which causes delays and increases risks and costs for investors. Finally, regulatory complexity and uncertainty, especially as markets need to integrate over a large geographic area, is a further inhibition to diversity in energy investments. These issues complicate the investment decision.

\section{The Future Energy Mix}

In aggregate the energy mix of developed nations is dominated by fossil fuels. Figure 1 provides the energy mix of developed countries in 2009 and a forecast of electricity consumption per day per person by generation type. Translating power consumption from annual total output to a daily measure corrected for estimated population growth is used to readily compare power consumption between nations at different stages of development. Coal and gas made up around 58 percent of consumption in 2009 which is forecast to remain largely steady out to 2025 , see IEA (2009). 


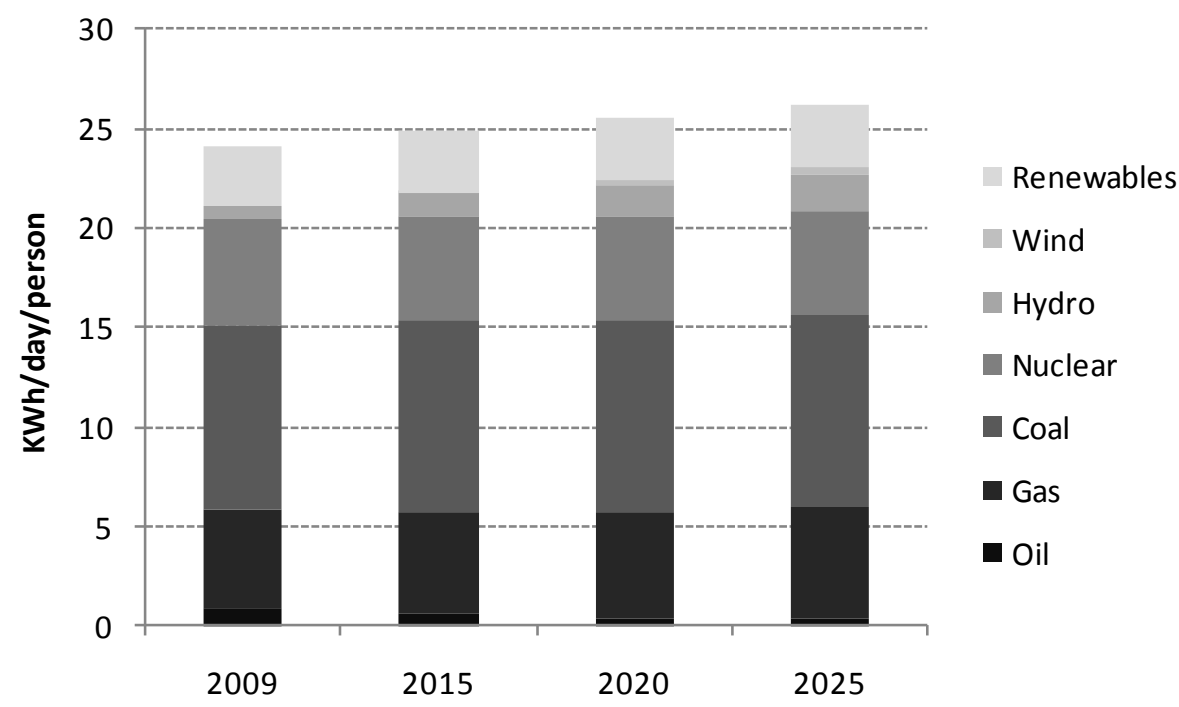

Figure 1: Forecast electricity consumption of developed countries 2009-2025 by generation type measured in power consumption per day per person. Assumes an energy intensity ceiling of $-2 \%$ and efficiencies in gas, coal, oil and wind plants remain static.

In line with developed nations, the energy mix of developing nations is also dominated by fossil fuels. Figure 2 provides the energy mix of developed countries in 2009 with a forecast of electricity consumption per day per person by generation type. Coal and gas made up around 67 percent of consumption in 2009 which is forecast to grow to over 71 percent by 2025 , see IEA (2009).

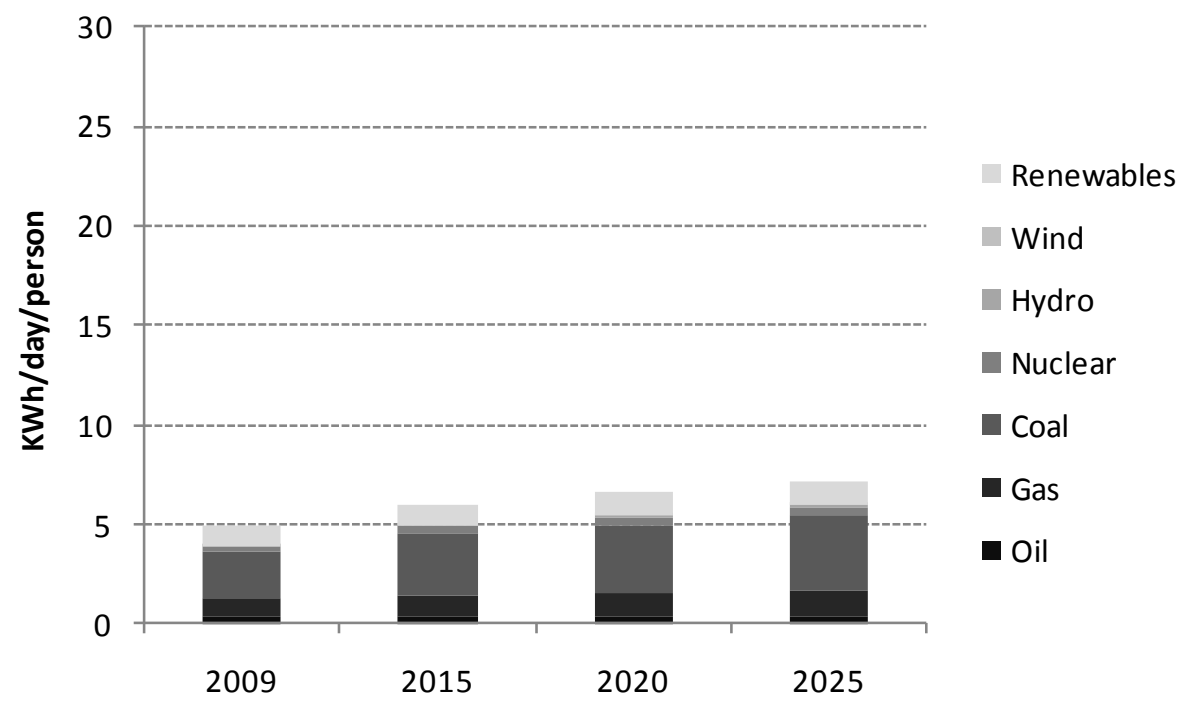

Figure 2: Forecast electricity consumption of developing countries 2009-2025 by generation type measured in power consumption per day per person. Assumes an energy intensity ceiling of -2\% and efficiencies in gas, coal, oil and wind plants remain static.

Globally coal and gas made up around 64 percent of consumption in 2009 which is forecast to grow to around 66 percent by 2025, see IEA (2009). Figure 3 illustrates global electricity consumption per day per person by generation type. According to the IEA forecast data no 
significant shift away from fossil fuels to renewable or nuclear electricity generation is expected out to 2025 .

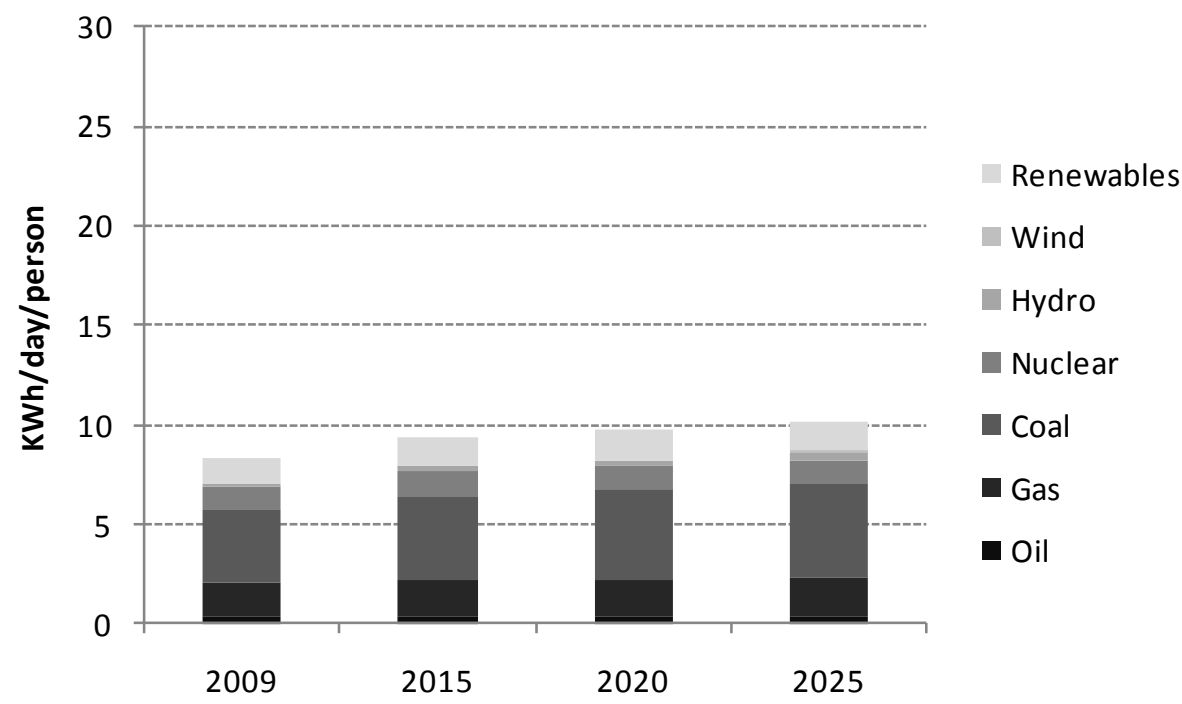

Figure 3: Forecast global electricity consumption 2009-2025 by generation type measured in power consumption per day per person. Assumes an energy intensity ceiling of $-2 \%$ and efficiencies in gas, coal, oil and wind plants remain static.

In 2009 global installed electricity generation capacity was 4,509 GW which produced 19,756 TWh of electricity, see IEA (2009). OECD countries' installed electricity capacity was 2,472 GW and electricity output was 10,641 TWh in 2007 which represents about 55 percent of world total. The OECD countries' proportion of global installed capacity and power consumption is expected to decline to around 40 percent by 2030 , which highlights the magnitude of the expected growth in the energy demand in non-OECD nations.

Energy intensity is a measure of the energy efficiency of an economy and is calculated as units of consumed energy per unit of GDP output. High energy intensities indicate a high or cost of converting energy into GDP while low energy intensities indicate the opposite. The energy intensity of OECD countries has historically been around 1.5 percent and is projected to continue out to 2030, see IEA (2009). However the energy intensity of the major developing nations is naturally expected to be higher and can be at sustained levels of around 3.5 percent for some countries. To illustrate the disparity between energy intensities of OECD and non-OECD nations, Figure 4 shows the history from 1998 and IEA forecast for energy intensity of Germany, the US, China and Russia. The intensity level of developing nations is expected to converge to that of developed nations from continual increases in energy efficiency and urban growth.

Energy demand is expected to continue to grow at a rate consistent with GDP growth, moderated by the efficiencies implied by improved energy intensity. The global energy mix is dependent on alternate energy technologies available the associated cost structure of each over the long term. 


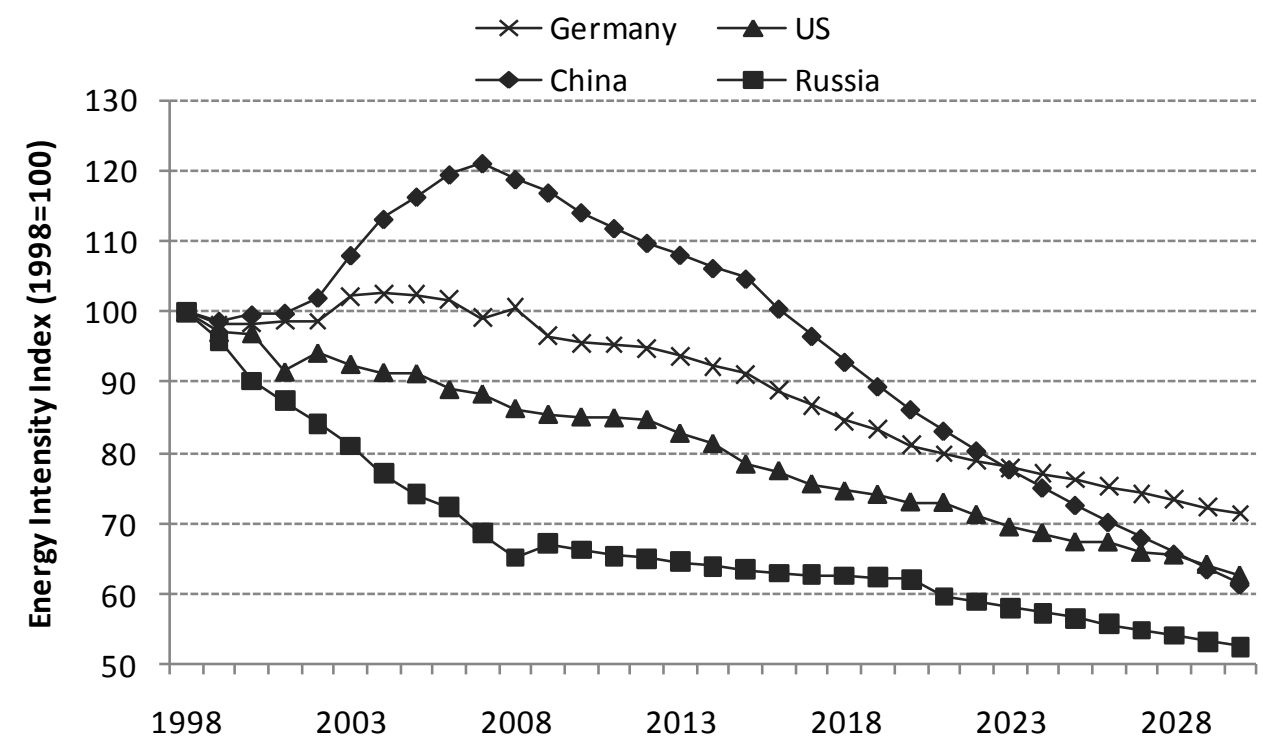

Figure 4: The energy intensity of Germany, US, China and Russia. Energy intensity is measured as power consumption per unit of GDP (TWh/US\$GDP) and converted to an index (1998 base year).

\section{LEVELISED COST OF ELECTRICITY GENERATION}

In this section we construct a levelised cost of electricity model for both developed and developing nations to validate the IEA energy forecasts and obtain levelised energy production cost estimates. Cost data was obtained for 260 power plants in 34 OECD and non-OECD countries and cross referenced against data from the International Energy Agency (IEA), the International Atomic Energy Agency, the Energy Information Administration and the European Energy Commission. This comprised 86 coal-fired power plants, 78 gas-fired power plants, 23 nuclear plants, 14 wind power plants, 12 oil plants and 28 hydro plants as well as 19 plants based on other fuels or technologies. The countries included in the analysis comprise over 80 percent of global power demand and over 90 percent of energy consumption using coal, gas, oil and nuclear fuel. Broad comparisons of energy efficiency, carbon intensity and construction costs are provided in Table 1 for both existing plants and the expected values of newer technologies. The technologies and plant types covered by the study include several units under construction or planned for commissioning between 2010 and 2015 for which cost estimates were developed.

\begin{tabular}{|c|c|c|c|c|c|c|}
\hline Generation Type & $\begin{array}{l}\text { Peak plant } \\
\text { availability }\end{array}$ & $\begin{array}{c}\text { Average } \\
\text { plant } \\
\text { availability }\end{array}$ & $\begin{array}{c}\text { Average plant } \\
\text { efficiency } \\
\text { (MWht/MWh) }\end{array}$ & $\begin{array}{c}\text { Carbon } \\
\text { intensity } \\
\text { (tCO2/MWht) }\end{array}$ & $\begin{array}{c}\text { Global } \\
\text { installed } \\
\text { capacity } \\
2009(\mathbf{G W})\end{array}$ & $\begin{array}{l}\text { Global average } \\
\text { power production } \\
1998-2010(\mathrm{TWh})\end{array}$ \\
\hline Oil & $96 \%$ & $92 \%$ & $35 \%$ & 0.28 & 445 & 1,117 \\
\hline OCGT \& GST & $95 \%$ & $90 \%$ & $35 \%$ & 0.20 & 350 & 2,888 \\
\hline CCGT & $94 \%$ & $88 \%$ & $56 \%$ & 0.20 & 817 & 1,238 \\
\hline Coal (USC) & $94 \%$ & $88 \%$ & $47 \%$ & 0.34 & 144 & 822 \\
\hline Coal (SC-large) & $94 \%$ & $82 \%$ & $37 \%$ & 0.34 & 432 & 2,465 \\
\hline Coal (SC-small) & $94 \%$ & $82 \%$ & $34 \%$ & 0.34 & 374 & 2,136 \\
\hline Lignite & $92 \%$ & $85 \%$ & $32 \%$ & 0.40 & 490 & 2,794 \\
\hline Nuclear & $96 \%$ & $81 \%$ & $34 \%$ & 0.00 & 371 & 2,719 \\
\hline Wind & $25 \%$ & $25 \%$ & $100 \%$ & 0.00 & 96 & 173 \\
\hline CSP & $20 \%$ & $20 \%$ & $100 \%$ & 0.00 & 9 & 5 \\
\hline Hydro & $60 \%$ & $20 \%$ & $100 \%$ & 0.00 & 923 & 3,078 \\
\hline
\end{tabular}

Table 1: Peak plant availability, average plant availability, average plant efficiency and carbon intensity assumptions by generation type. Global total average annual power production by generation type over 1998-2010 is provided in the last column. 
Input fuel prices constitute a significant component of generation costs. An accurate set of price input data is required that is not only consistent by commodity type but also across the portfolio of fuels in the energy complex. To maintain a consistent approach an average of energy commodity price forecasts for both domestic and internationally traded fuels was obtained from from UBS, Deutsche Bank, Credit Suisse, Macquarie Bank, Rio Tinto and BHP Billiton. The price history and forecast for input fuels in MWh thermal as at end-2010 is provided in Figure 5. Countries that primarily rely on domestic sources of fuel such as South Africa and Australia will typically have a significantly lower cost associated with fuel than countries that rely on imported fuels such as Japan and countries in Western Europe. The fuel price component of the levelised prices reflects this differential.

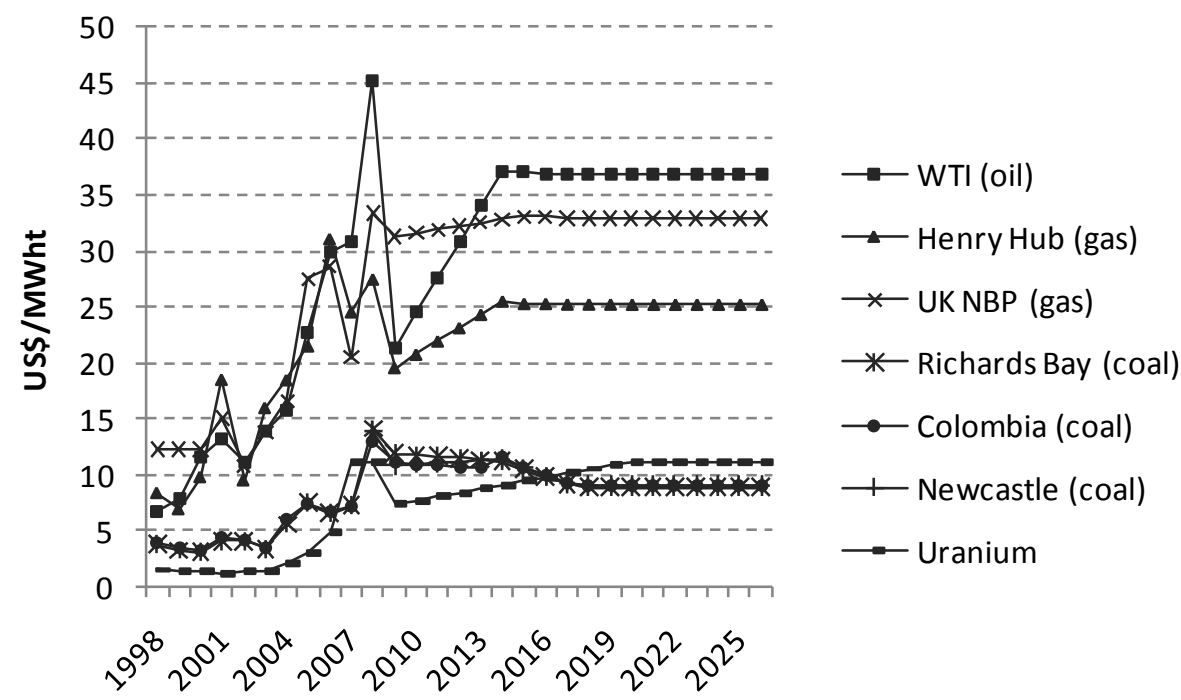

Figure 5: Price history and forecast of input fuels in MWh thermal (no adjustments for different plant efficiencies) 1998-2025.

Capital costs were taken from a joint McKinsey and BHP Billiton electricity generator database which contains a set of benchmarked 2008 capital expenditures. Additional proxies were created for some non-OECD countries with adjustments to the labour component of capital expenditure. For capital intensive plants (nuclear and renewable energy) the major drivers of levelised costs are overnight capital expenditures (engineering-procurement-construction plus owners' costs but excluding financing, escalation of material and labour costs and inflation), the build time and the average annual plant capacity. For the more expensive fuel converters (coal, gas and oil) the primary drivers of costs are the efficiency of fuel conversion, the price of fuel and the impact of the carbon penalty, which is considered as a separate component in this analysis. For coal-fired power plants the level of plant utilisation is a major issue given that thermal coal is generally priced well below gas on a burner tip basis and the capital requirements of fired-boiler-steam turbine combinations are much greater than gas turbine-based technologies. Adding carbon capture and storage to a coal (or CCGT) plant further shifts the balance towards capital costs due to the increased capital burden in net output terms. Fuel costs would also go up with CCS though due to the decreased conversion efficiency rates. Escalation indices were obtained from the IEA, EIA and the Nuclear Energy Institute and applied to capital expenditure costs for construction per region (Europe, Asia, other OECD, and other non-OECD). An example of European escalation indices is provided in Figure 6. 


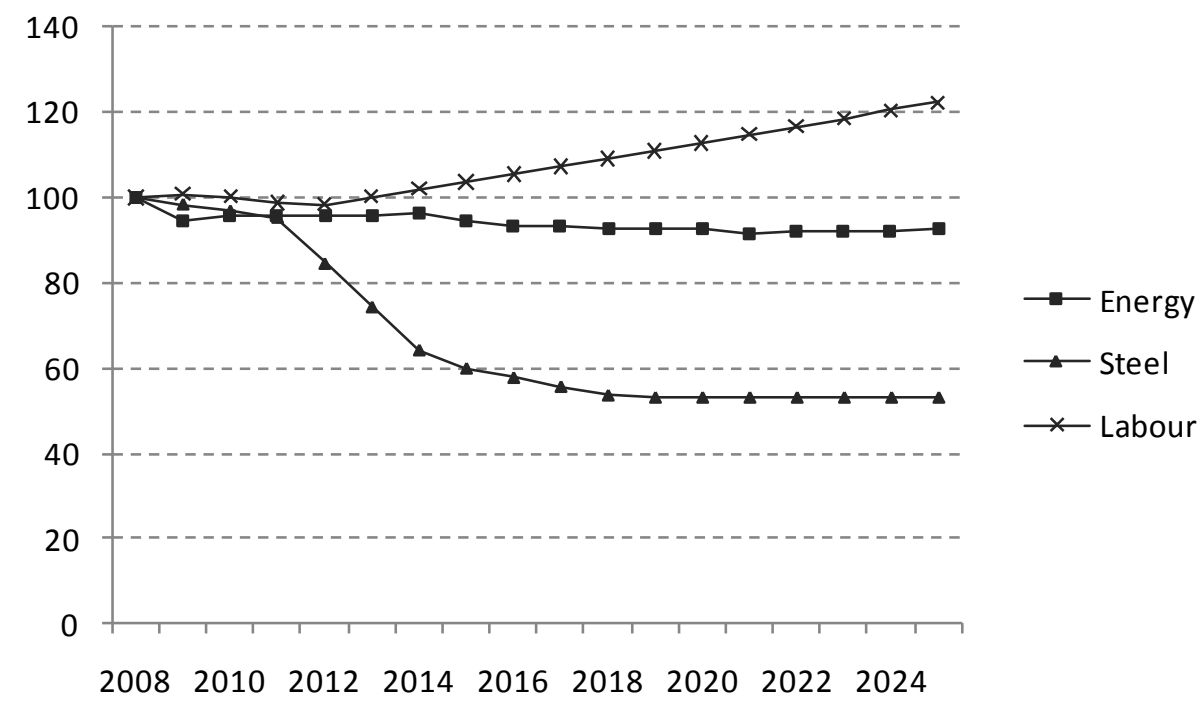

Figure 6: European escalator indexes are applied to labour, energy price and steel to produce capital expenditure forecasts 2008-2025, IEA 2009.

Figure 7 provides a representative cost breakdown in US\$ per kilowatt hour of capital costs for European-based generators. All capital expenditures have been broken down into escalator components to produce capital expenditure forecasts. Clearly labour, steel and concrete comprise the majority of capital costs requiring accurate escalator indexes to forecast future costs.

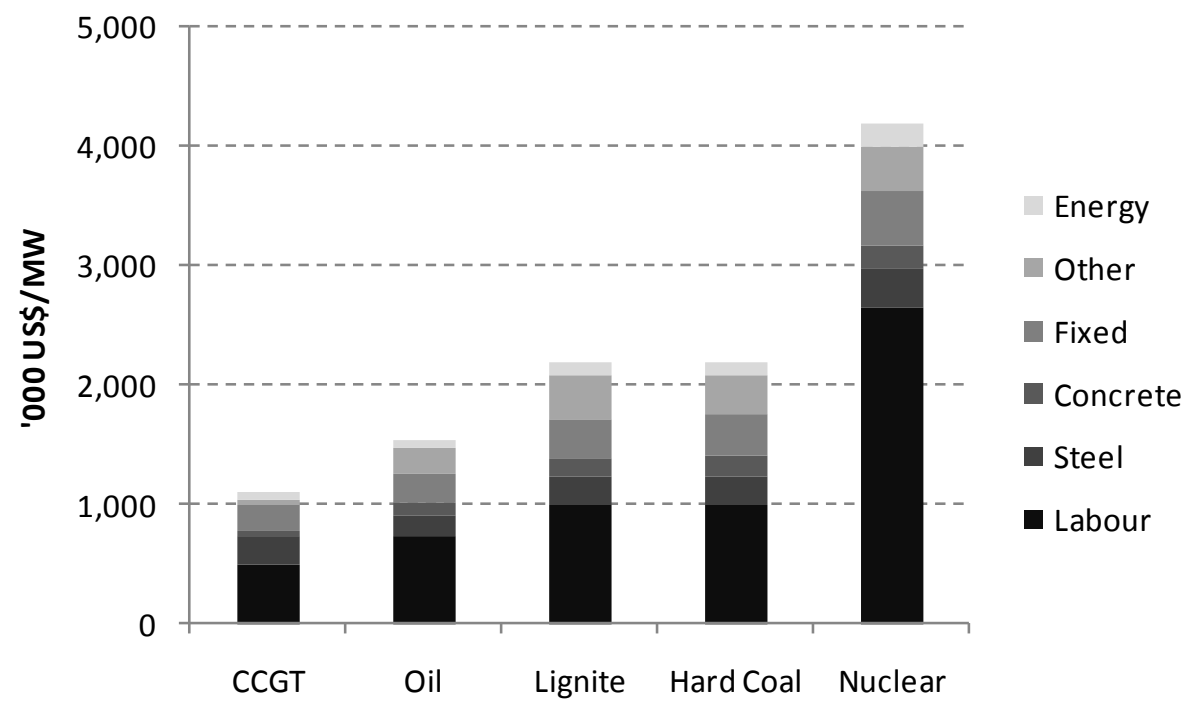

Figure 7: European capital expenditure components by generator type in millions of US\$ per MW, 2009.

\section{EMPIRICAL MODEL}

To estimate the levelised cost of production we must assess the relationship between actual power prices and actual short-run and long-run costs, and then forecast how this relationship is likely to develop over the forecast period to determine a corresponding power price forecast. This process is conducted separately for OECD and non-OECD countries. 
The levelised cost of electricity generation is defined as the ratio of the net present value of total capital and operating costs of a particular plant to the net present value of the net electricity generated by that plant over its operating life. The levelised cost for technology $k$ in country $j$ can be described as follows:

$$
\text { Levelised } \operatorname{Cost}_{k, j}=\frac{P_{C+O}^{k, j}}{P_{G}^{k, j}}
$$

where

$$
P_{C+O}^{k, j}=\sum_{i=1}^{n} \frac{T C_{i}^{k, j}}{\left(1+r^{k, j}\right)^{i}}
$$

where $n$ is the number of years used in the levelised cost analysis, TC is the total capital, operating, fuel and emissions cost for technology $k$ in country $j$ and $r$ is the weighted average cost of capital for technology $k$ in country $j$, and

$$
P_{G}^{k, j}=\sum_{i=1}^{n} \frac{G_{i}^{k, j}}{\left(1+r^{k, j}\right)}
$$

where $G$ is the total generation value for technology $k$ in country $j$. The levelised cost therefore represents a minimum breakeven tariff expressed in US\$/MWh for each plant by country, based on a set of assumptions discussed below and discount rate chosen (weighted average cost of capital). The levelised cost is broken down into the contribution from capital costs, fixed operating costs, fuel and carbon costs and non-fuel operating costs.

Levelised power production prices are derived using the following process:

1. The short run marginal cost (SRMC) of electricity is calculated by aggregating fuel prices, emissions costs and variable operating and maintenance (O\&M) costs by plant type;

2. the long run average cost (LRAC) of electricity anchored at 2030 is aggregated from the SRMC, fixed O\&M costs and capital costs by plant type;

3. new-build plant capacity is then calculated by estimating planned additions and retirements, as well as any forced new-builds with the balance of any power deficit based on a ranking of allowed new-build technologies;

4. the average SRMC is then calculated from the load duration curve and the proportion of time for which each generation type is marginal;

5. the same process is then repeated for average LRAC; and

6. the expected power price is then forecast based on a combination of SRMC and LRAC.

The calculations use generic assumptions for the main technical and economic parameters such as the economic lifetime of different plants, the average load factor for base-load plants and an appropriate discount rate. A selection of some main assumptions used in the analysis of OECD countries is provided in Table 2 . 


\begin{tabular}{|l|c|c|c|c|c|}
\hline Generation Type & $\begin{array}{c}\text { Construction } \\
\text { cost } \\
\text { (US\$/MWh) }\end{array}$ & $\begin{array}{c}\text { Average } \\
\text { construction } \\
\text { cost growth } \\
\mathbf{( 2 0 1 0 - 2 0})\end{array}$ & $\begin{array}{c}\text { Average } \\
\text { plant life } \\
\text { (yrs) }\end{array}$ & $\begin{array}{c}\text { Average age } \\
\text { of existing } \\
\text { assets }\end{array}$ & $\begin{array}{c}\text { Employees } \\
\text { per MW }\end{array}$ \\
\hline Oil & 983,400 & $-2.28 \%$ & 40 & 23 & 0.10 \\
\hline OCGT \& GST & 376,200 & $-2.74 \%$ & 40 & 18 & 0.14 \\
\hline CCGT & 756,860 & $-2.74 \%$ & 40 & 10 & 0.10 \\
\hline Coal (USC) & $1,533,700$ & $-2.32 \%$ & 50 & 7 & 0.15 \\
\hline Coal (SC-large) & $1,280,400$ & $-2.32 \%$ & 50 & 27 & 0.15 \\
\hline Coal (SC-small) & $1,280,400$ & $-2.32 \%$ & 50 & 33 & 0.15 \\
\hline Lignite & $1,405,800$ & $-2.33 \%$ & 50 & 30 & 0.15 \\
\hline Nuclear & $4,020,000$ & $-5.64 \%$ & 50 & - & 0.20 \\
\hline Wind & $1,635,020$ & $-5.69 \%$ & 100 & 3 & 0.00 \\
\hline CSP & $3,502,640$ & $-6.72 \%$ & 100 & - & 0.00 \\
\hline Hydro & $1,410,000$ & $-2.03 \%$ & 100 & 40 & 0.15 \\
\hline
\end{tabular}

Table 2: Construction cost and cost growth rates, plant life, existing asset age and number of employees required per MWh assumptions by plant type for OECD countries.

Assuming a typical debt to total capital ratio of 60 percent and a credit rating of $\mathrm{BBB}+$, data from Moody's Research indicates that an appropriate average cost of capital on electricity generation investments is in the range of 9.8-10.6 percent for OECD countries with non-OECD countries attracting an additional risk premium of around 2 percent. This cost ignores the technology risk premium for alternate energy sources. For ease of analysis a common weighted average cost of capital of 12 percent is therefore used for both OECD and non-OECD countries and a country risk premium is applied to each country's levelised cost estimates. The country risk premium was obtained from Moody's Research. It is possible to apply different discount rates to the various components of the costs, for example one for operations and maintenance and one for input fuel, to obtain a present value of the cost streams that reflects the risk differentials of each component, see Awerbuch (1996). However this approach has a high propensity to induce compounded errors through construction of the discount rate and therefore is not used in this analysis.

Electricity generation costs are busbar costs at the station and do not include transmission and distribution costs, which can substantially affect consumer prices particularly in geographically larger countries. The costs associated with residual emissions, including greenhouse gases, are included as part of the estimated generation costs and are considered separately in the comparative analysis. An initial CO2 price of US\$25/t growing at 4 percent per annum for OECD countries and a zero price for non-OECD countries is assumed for this analysis. This price and forward growth rate was calculated as an average of the analyst commodity price forecasts and growth expectations discussed in reference to the price assumptions in Figure 5.

\section{Learning Rates}

Awerbuch (1996) has claimed that actual levelised costs can be biased away from newer technologies as the pace of technological innovation increases. To counter this argument learning rates are included in the capital expenditure projections. The learning rate $L\left(P_{C+O}\right)$ is assumed to be a strictly concave function such that $L^{\prime\left(P_{C+O}\right)}<0$ and $L^{\prime \prime\left(P_{C+O}\right)}>0$.

Learning rates are important for newer technologies as these will drive down the cost of additional units. For mature technologies such as gas and coal-fired power there is likely to be comparatively little difference between the first of a kind (FOAK) and the $n$th of a kind (NOAK) plant. It can be argued that the more advances coal and gas power technologies are already at the NOAK level, as is onshore wind. Offshore wind still has some significant learning, especially in the area on cost effective foundations/anchoring and in reducing maintenance and servicing costs. Third generation nuclear plants, concentrated solar and CCS are at an earlier stage although for 
nuclear there are likely to be more efficiencies gained through improved project management rather than changes in the technology, see Nuclear Energy Institute (2008). Solar technology was assigned an annual learning rate of 20 percent, nuclear technology was assigned a global annual learning rate of 6 percent for newer technology and no learning for old technology while wind was assumed to have an annual learning rate of 15 percent. CCS technology was not included in the analysis as the time horizon for commercialisation lies beyond 2025. The learning rates for both OECD and non-OECD countries for solar, nuclear and wind are shown in Figure 8.

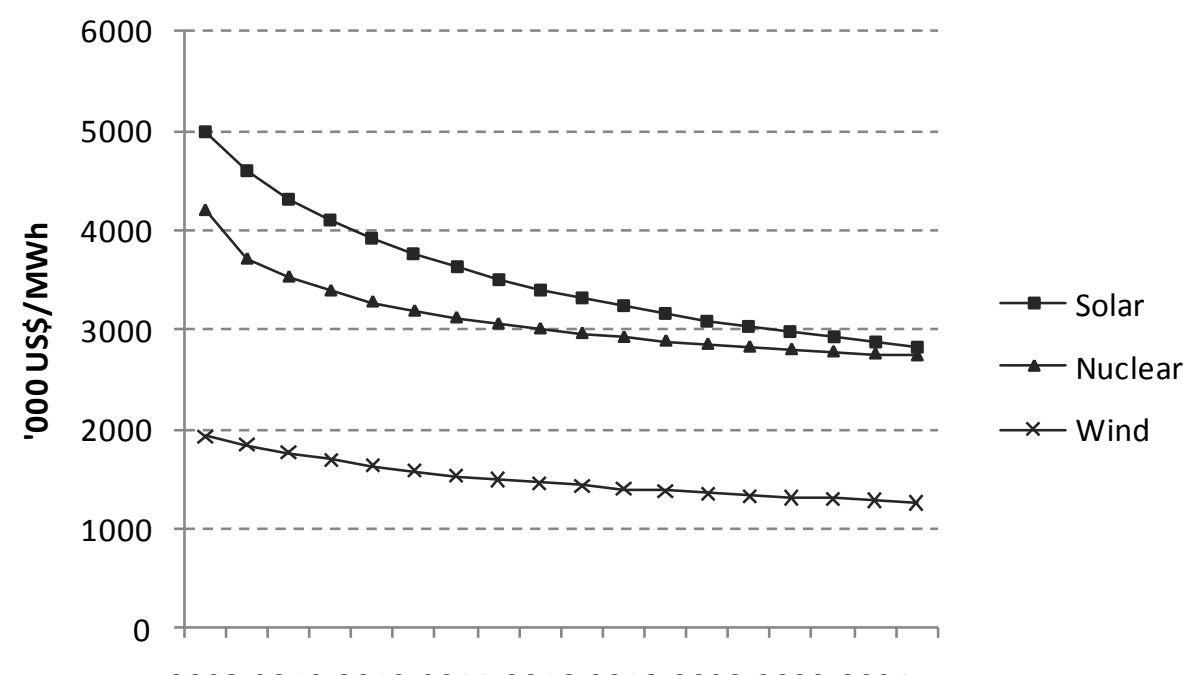

200820102012201420162018202020222024

Figure 8: Capital expenditure cost decrease due to learning effects in US\$/kW 2008-2025.

The average capital cost and variation among OECD and non-OECD countries is shown in Figures 9 and 10 respectively. Non-OECD countries exhibit much greater variation in construction costs due to the challenges associated with geography, labour, government regulation and existing industry. 


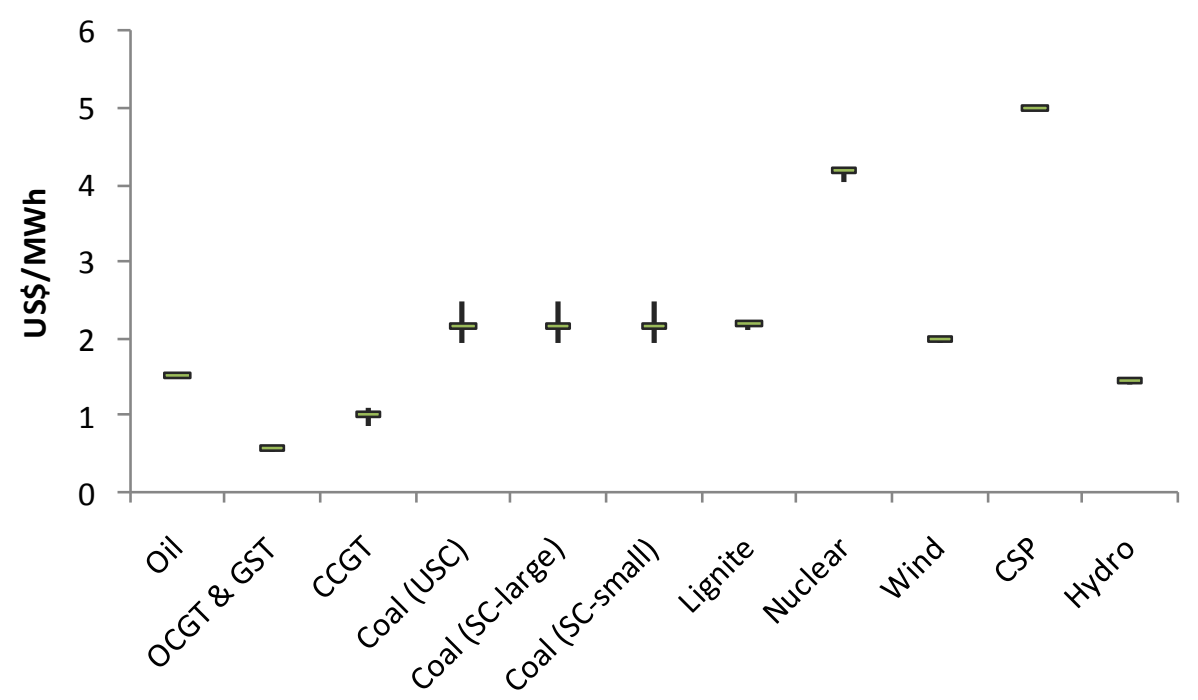

Figure 9: The high, low and average capital cost for different generation technologies in OECD countries 2010-2030 (US\$/MWh). [OCGT - Open Cycle Gas Turbine, GST - Gas Steam Turbine CCGT-Combined Cycle Gas Turbine, USCUltra Super Critical, SC Super Critical, CSP - Concentrated Solar Power].

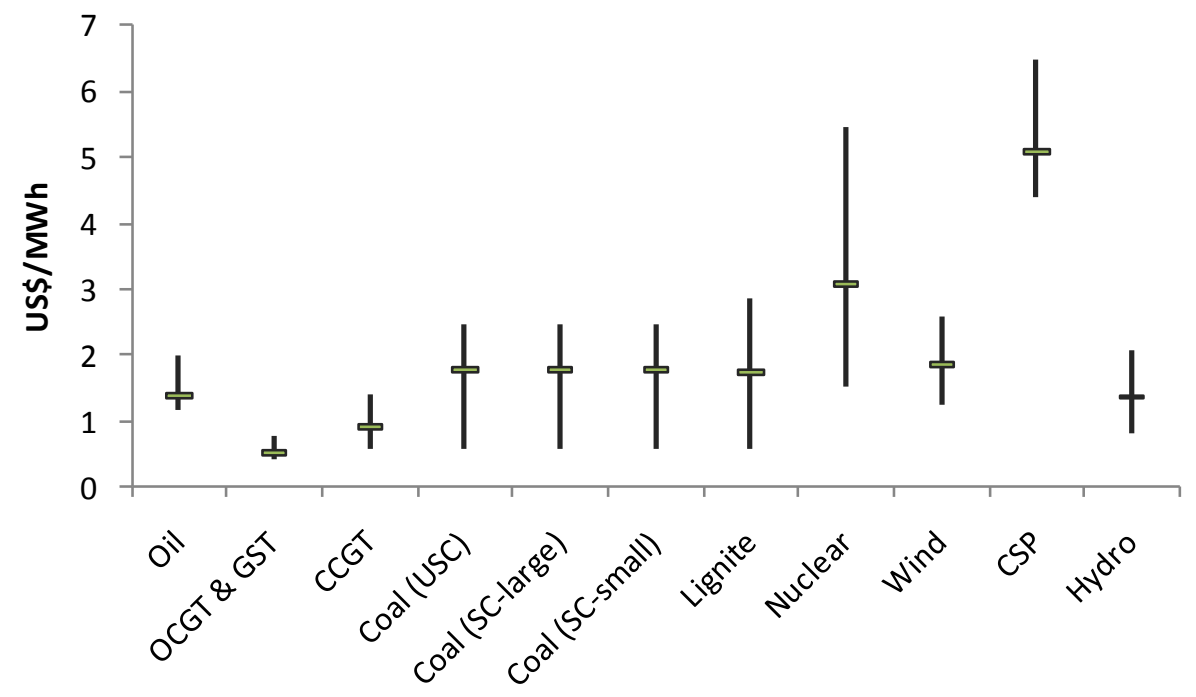

Figure 10: The high, low and average capital cost for different generation technologies in non-OECD countries 2010-2030 (US\$/MWh). [OCGT - Open Cycle Gas Turbine, GST - Gas Steam Turbine CCGT-Combined Cycle Gas Turbine, USCUltra Super Critical, SC Super Critical, CSP - Concentrated Solar Power].

A variety of components are excluded from the levelised cost estimates. Some of these factors could be included by adjusting one or more of the capital or operational cost elements described above, so that they act as a proxy for the 'missing' elements. Exogenous impacts such as the value of government funded research programmes, residual insurance responsibilities and external pollution costs were explicitly ignored in the analysis. The system factors that were excluded include transmission and other network costs, costs associated with providing energy security, flexibility and management of power station output and the relative impact of demand variation. The business impacts excluded from the model include option values of investments in a particular technology, effect of project size, scale and modularity, the fact that plant lifetime may exceed economic life, fuel price volatility, regulatory changes and corporate taxes. The 
impact of a combination of these factors could have some impact on the levelised cost of generation however estimating the probability of such impacts while difficult is assumed to be immaterial for this analysis.

\section{RESULTS}

The average levelised cost of energy by generating type for OECD countries over the period 2010-25 is illustrated in Figure 11.

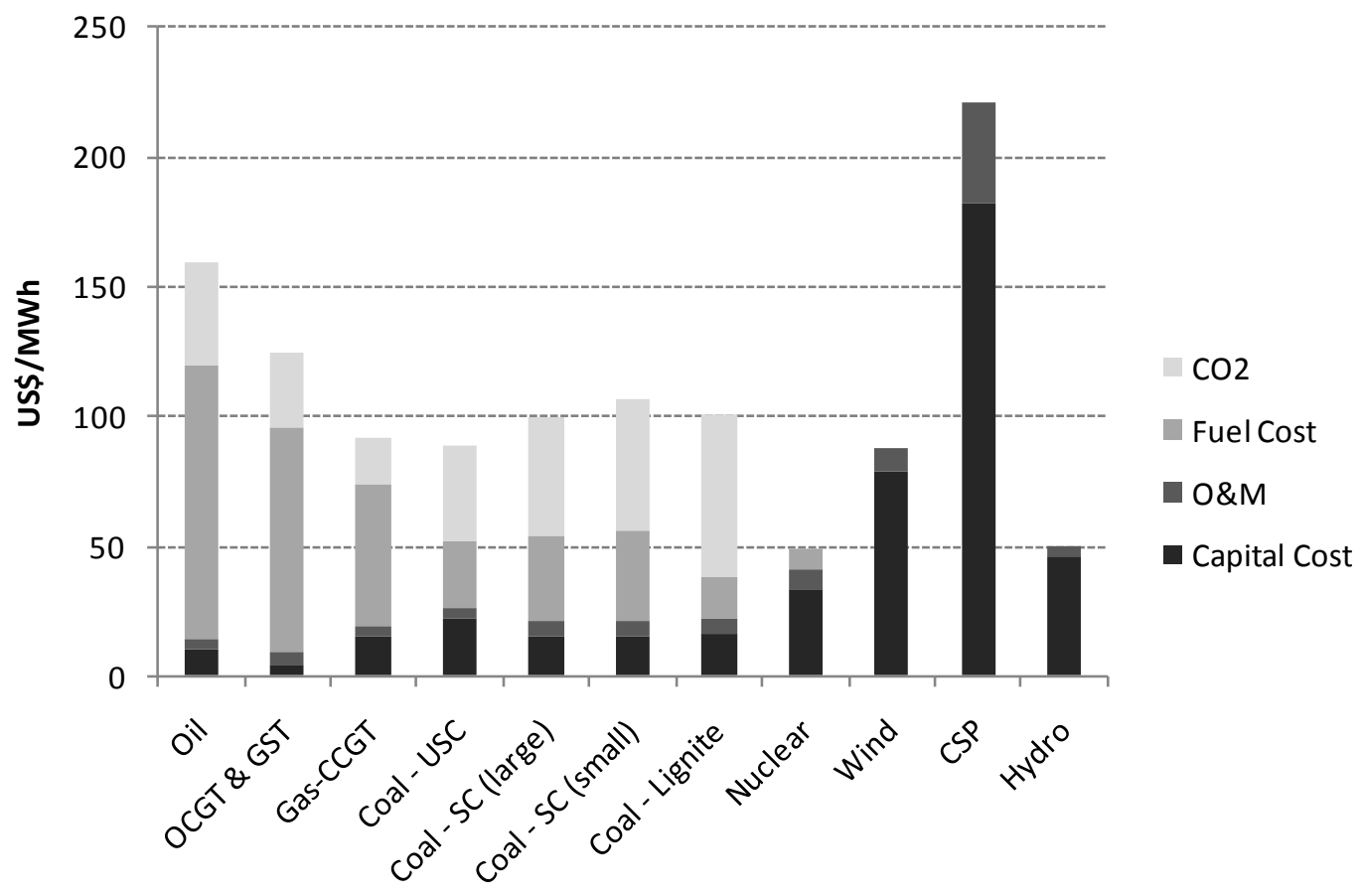

Figure 11: The cost breakdown of the average levelised long run marginal cost of electricity generation in OECD countries 2010-2025 (US\$/MWh). Nuclear O\&M cost includes a decommissioning expense of 3.8 US\$/MWh included in O\&M [OCGT - Open Cycle Gas Turbine, GST - Gas Steam Turbine CCGT-Combined Cycle Gas Turbine, USC - Ultra Super Critical, SC Super Critical, CSP - Concentrated Solar Power].

The average levelised cost of energy by generating type for non-OECD countries over the period 2010-25 is illustrated in Figure 12. 


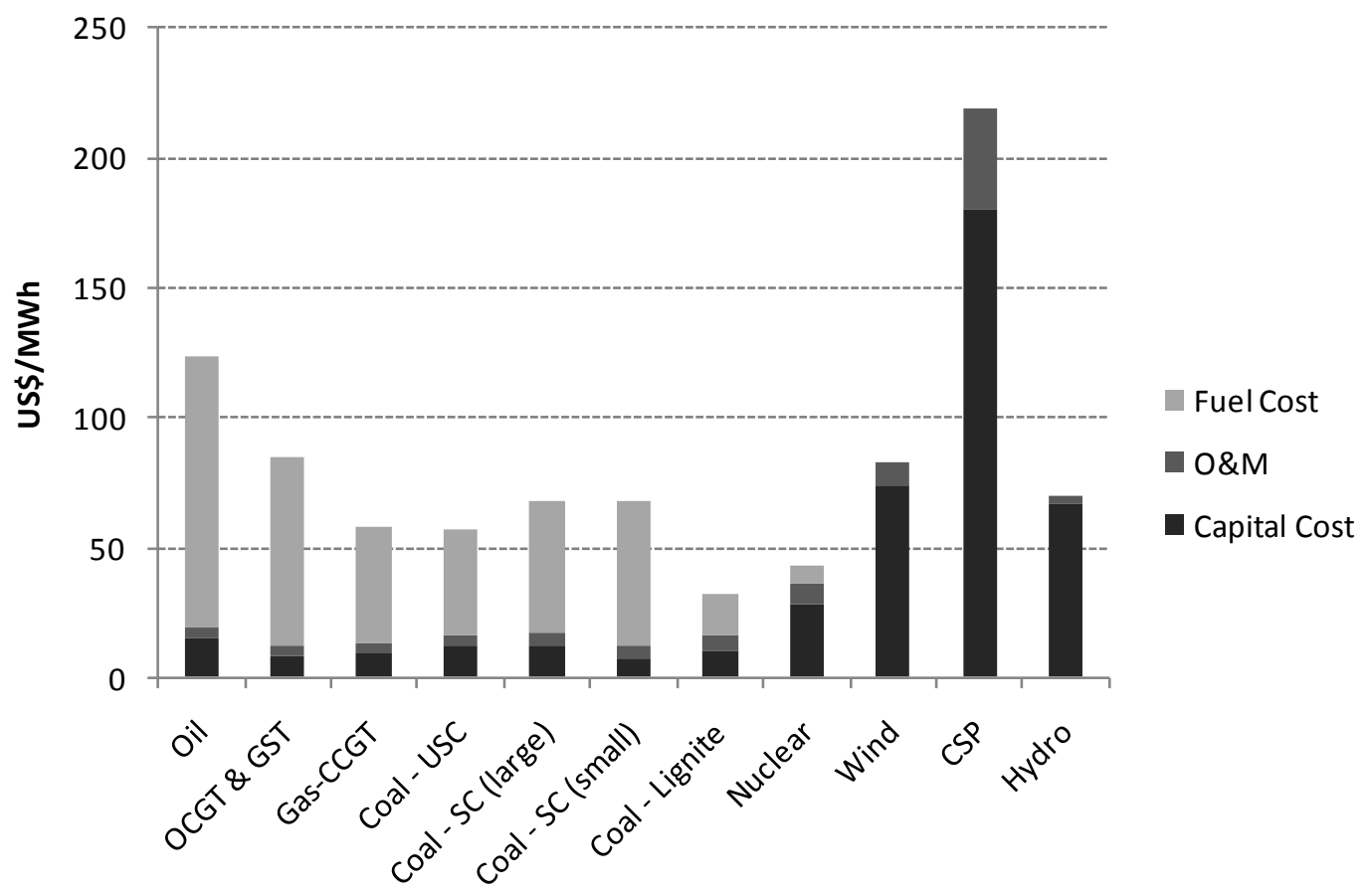

Figure 12: The cost breakdown of the average levelised long run marginal cost of electricity generation in non-OECD countries 2010-2025 (US\$/MWh). Nuclear O\&M cost includes a decommissioning expense of 3.8 US\$/MWh included in O\&M [OCGT - Open Cycle Gas Turbine, GST - Gas Steam Turbine CCGT-Combined Cycle Gas Turbine, USC - Ultra Super Critical, SC Super Critical, CSP-Concentrated Solar Power].

These figures provide a graphical comparison of the component levelised generation costs and provide a clear comparison between generation types. Direct emissions prices are not considered for non-OECD countries since the likelihood of emissions costs being applied to the electricity industry by 2025 is expected to be low. Simple sensitivity analysis can be performed to derive costs under different capital cost, fuel cost and climate change policy change scenarios. Sensitivity analysis has not been explicitly performed as part of this analysis however general generation cost comparisons can be made.

\section{Oil-based technologies}

Oil-based generation is primarily used to power small and/or isolated communities such that the transmission costs from a distant grid are prohibitively expensive. While this type of generation serves a purpose it is not an economically sustainable long-term option for regions experiencing significant growth in power demand. Oil-based technologies as a competing generator are not considered further in this analysis.

\section{Coal-fired generating technologies}

Most coal-fired power plants have construction costs ranging between US\$1.5-2.5 million per MWh in OECD countries down to around US\$0.6m-2m in non-OECD countries. Construction times are around four years for most plants. Some OECD countries like Australia and the US have abundant supplies of fuel (black coal, brown coal or lignite) such that power generators can use run of mine coal at delivered costs of around US\$35 per tonne with a high expectation of long term price stability. Other OECD members like Japan and EU countries have very little fuel and must pay market prices for seaborne coal, which are projected to remain at prices in excess of 
US\$60 per tonne to 2030 . Non-OECD countries that rely on imported coal will pay much higher prices than countries with abundant fuel which induces some bias in the analysis. For instance, Chinese domestic coal prices are comparable with seaborne prices however Indian domestic coal prices are significantly lower than the seaborne index.

Levelised generation costs in OECD countries range between US\$40-80/MWh for most coalfired power plants compared with US\$25-70/MWh in non-OECD countries. Generally, investment costs represent around one-half of the total while operating and maintenance costs account for 15 percent and fuel for around 35 percent. Emissions costs push the levelised cost to over US\$90/MWh for the most efficient coal-fired power plants which represents a significant difference against the non-OECD countries generation costs. Given that coal is likely to remain a significant component of non-OECD countries' energy mix this is likely to induce the migration of high emissions intensity industries from high-cost to low-cost power producers where emissions are unpriced.

Carbon capture and storage technology has the potential to change to nature of the energy mix to favour coal-fired generation. From the modelling conducted under the levelised cost model the inducement cost for emissions would have to be around US\$60-80/t for CCS to become economical over the longer term. Unless significant government subsidies can be deployed to bridge the cost gap, a long term emissions price of US\$60/t does not appear likely given the cost of alternative generation sources available.

\section{Gas-fired generating technologies}

For gas-fired power plants construction costs for OECD countries in most cases range between US\$0.5-0.8 million per MWh compared with slightly lower construction costs in non-OECD countries ranging between US\$0.4-0.8m/MWh. The construction costs of gas-fired plants are considerably less than those of coal-fired and nuclear power plants. Gas-fired plants are built rapidly with expenditures spread over one-and-a-half to three years. The operating and maintenance costs of gas-fired plants are also significantly less than coal or nuclear plants. However the low gas price in $2009-10$ of between US\$3.5-4.5/GJ is adjusted in the analysis to cater for expectations of significant escalations in the longer-term gas price.

The levelised costs of gas-fired plants range between US\$70-90 per MWh for OECD countries and US\$60-80/MWh for non-OECD countries due to lower labour and storage costs. Fuel cost is the major contributor representing 73 percent of total generation cost, while investment and operating/maintenance shares are around 20 percent and 7 percent respectively. Emissions costs push the levelised cost to around US $\$ 88 / \mathrm{MWh}$ for OECD countries making gas very competitive against coal-fired generation. The expected absence of emissions costs in non-OECD countries implies a levelised generation cost of US\$55-80/MWh which is also competitive against coalfired generation in non-OECD countries. Gas prices however are expected to be more volatile than coal in the 2010-2025 period due to high growth in extraction costs, discoveries and new extraction technologies of shale gas in northern America and uncertainty around the long term energy investment policies of the three gas-rich regions of Russia, Iran and Qatar.

\section{Nuclear generating technologies}

For nuclear power plants investment costs, not including refurbishment or decommissioning, are subject to very large variations between US\$2-6 million per MWh for most plant types in OECD countries. Non-OECD countries also have large variation between the expected construction costs and most range between US\$2-5.4m. Build times for nuclear plants have varied with a few 
stations in the UK and USA taking well over ten years to complete. French constructors have achieved an average build time of 6.7 years while globally since 1993 build time has shortened to around 5.3 years, see Nuclear Energy Institute (2008). This improvement reflects the increased influence of Chinese and East Asian projects. Shorter timelines are unlikely to be achieved not least because of material and component lead times. For instance an essential reactor nozzle ring order placed today has a lead time of around 5 years. In the long term bottlenecks in component parts should ease and the assumption used in the model is that the build times for a NOAK plant will approach 4 years by 2025. Some non-OECD countries such as China have very advanced nuclear power expansion programs in place and have successfully been able to consistently reduce the construction times to less than 5 years without necessarily compromising safety standards.

Decommissioning costs are about $9-15 \%$ of the initial capital cost of a nuclear power plant see Nuclear Energy Institute (2008) but when discounted, contribute only a few percent to the investment cost and even less to the generation cost. In the USA they generally account for US\$1-2/MWh, which is no more than about 2 percent of the cost of the electricity produced. The fuel cost figures include used fuel management and final waste disposal. These costs, while usually external for other technologies, are internal for nuclear power. The back-end of the fuel cycle, including used fuel storage or disposal in a waste repository, therefore contributes up to 10 percent of the overall costs per MWh.

It is expected that 90 percent or more of total expenses are incurred within five years or less while power output may be a further 5 years away. The levelised costs of nuclear electricity generation as computed in the model are expected to be around AU\$50-65 per MWh in OECD countries and slightly less in non-OECD countries. The share of investment in total levelised generation cost is around 70 percent while the other cost elements, operating and maintenance and the fuel cycle are estimated to represent on average 20 percent and 10 percent respectively. Investment costs include estimates for refurbishment and decommissioning as well as interest costs during construction. Using the levelised cost approach nuclear power has a clear advantage over fossil fuel technologies. However caution is required since the limited availability of capital cost data for nuclear new builds makes it difficult to calibrate the long term costs accurately and nuclear power plant construction expenditures are known to exceed budgets. However zero emission costs allow nuclear to be very competitive against coal and gas generation levelised prices.

The project-based WACC of nuclear projects tends to be lower due to typically high debt capital structures and the provision of loan collateral. Historically, utility companies in Western countries do not generally proceed with a nuclear new build without government loan guarantees which can be difficult to secure in some regions. Public opposition to nuclear power generation is another serious obstacle for some countries.

\section{Wind generating technologies}

Wind power plant construction costs for both OECD and non-OECD countries can range anywhere between US\$1-2 million per MWh depending on location (onshore or offshore). Existing build schedules indicate a construction period of between one to two years. The costs calculated for wind power plants are based on the levelised lifetime methodology used for other technologies to maintain consistency. For intermittent renewable sources such as wind the availability/capacity of the plant is a key driving factor for computing the levelised cost of electricity generation. The observed availability and capacity of wind power plants ranges between 17-38 percent for onshore plants and between 40-45 percent for offshore plants, see West (2011). The levelised costs for wind power plants are estimated to range between US\$45- 
145 per MWh but for many plants the costs are around US\$95-100 per MWh for both OECD and non-OECD countries. The share of operating and maintenance costs of the total ranges between 15-40 percent depending on location.

The levelised cost does not reflect ancillary costs associated with the need for backup power to compensate for the low average availability factor for wind as compared to existing baseload plants. Furthermore wind is limited not only as an intermittent source, but has an associated high probability that on peak energy use days (when it is very hot or very cold) wind speeds tend to be lower than usual, see West (2011). Transmission investment would also be required since wind resources tend to be far from where the electricity is consumed. Distribution costs are not considered in this analysis however as an indication, a US\$1 billion investment for an $800 \mathrm{~km}$ transmission line could add up to US\$20 per MWh to the levelised cost of electricity.

\section{Hydro generating technologies}

The hydro power plants considered in the study ranged from very large to very small units. The levelised costs for hydroelectricity generation range between US\$65-100 per MWh for most plants in OECD countries. The analysis found that levelised costs of generation are in fact higher for non-OECD countries by at least US $\$ 10$ per MWh indicating the impact of an escalation in capital costs for new generating units compared with the sustaining capital costs of existing units. This technology remains competitive but has limited capacity for baseload generation in most countries and especially for non-OECD countries.

\section{Solar generating technologies}

For large-scale concentrated solar plants the availability/capacity factors reported vary from 9-24 percent. At a higher capacity/availability factor the levelised costs of solar-generated electricity are around US\$200 per MWh while lower availability/capacity factors translate into a levelised cost above US $\$ 300$ per MWh. The analysis includes a 20 percent learning rate discount to capital costs to allow for technology improvements through time. Concentrated solar is uncompetitive compared with both fossil fuel generators and renewable energy alternatives.

Small-scale solar units in the form of photovoltaic cells can avoid grid-related capital expenditures which can make solar power cost competitive, however only large scale projectspecific investments are considered in this analysis.

\section{Other generating technologies}

Fringe energy sources such as geothermal, combined heat and power systems, tidal and biomass also warrant brief consideration. Geothermal energy appears to be an attractive energy source because it is 'always on' and independent of the weather. The difficulty with sustainable geothermal power is that the speed at which heat travels through the solid hot rocks in the earth's interior limits the rate at which heat can be sustainably extracted. Time delays occurring between the injection of cold water pumped into the earth's interior and the extraction of steam to run a turbine mean that on average, geothermal energy is probably unsustainable as a long term energy source in most countries. Geothermal energy is also highly dependent on the location of suitable sites.

The total levelised costs of generating electricity for combined heat and power plants are highly dependent on the use and value of the combined product. Heat and power plants are also very site 
specific and levelised costs are expected to range between US\$90-120 per MWh. Reliable information on the construction costs and capacity/availability of large-scale tidal and biomass plants are not available and have not been explicitly considered for this analysis. It is unlikely that either technology will be commercially viable on a large scale in the next 20 years, see West (2011).

\section{Price Convergence and Carbon Intensity}

The model forecasts a high degree of price convergence among both OECD and non-OECD countries as shown in Figure 13. Regions with a significant price advantage will experience rapidly rising generation prices as capital, emissions and input fuel costs escalate in line with the forecasts provided earlier. South Africa and India will see the greatest price change in generation costs primarily caused by both rising coal and gas prices and Australia and the US will experience price increases due to an expected price placed on emissions in each country by 2020.

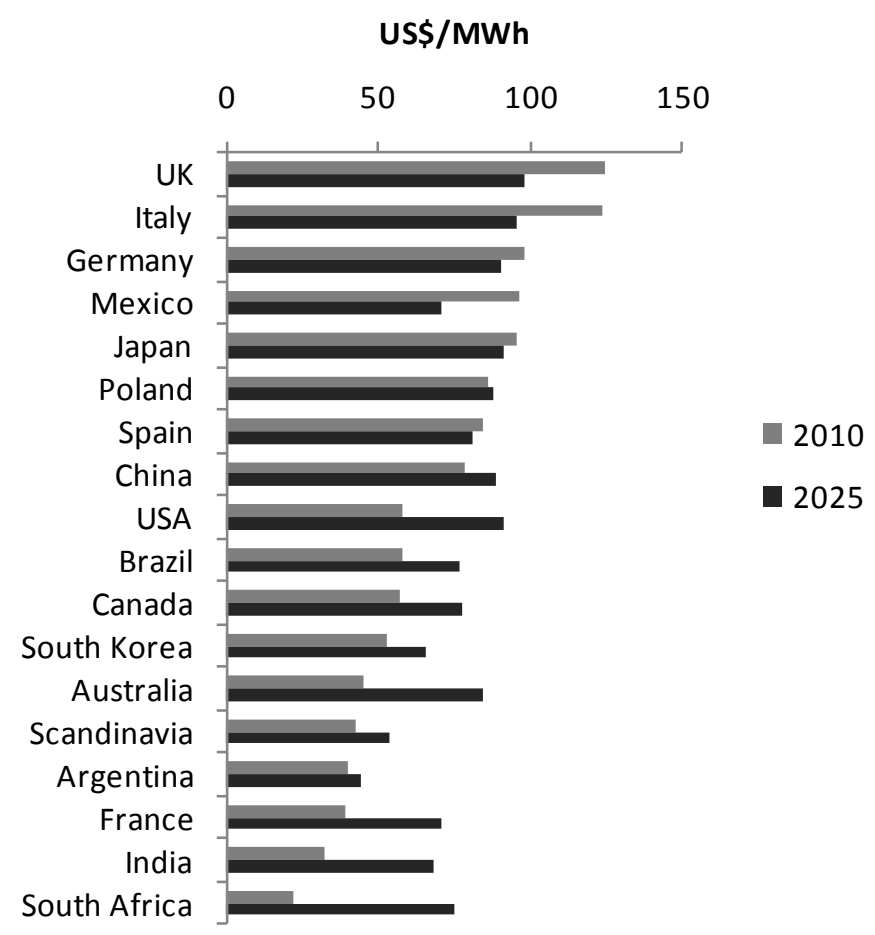

Figure 13: Wholesale electricity prices for 2010 against modelled prices for 2025 for the OECD and non-OECD countries included in the model.

The model highlights however that carbon intensity in many countries will be reduced with the gradual shift towards less $\mathrm{CO} 2$ emitting power technologies such as nuclear and wind. Figure 14 illustrates the carbon intensity shift for several countries relative to the global average. A degree of carbon intensive industry migration from OECD to non-OECD countries will occur however the efficiency of such a change is difficult to estimate. However the model covers 90 percent of current global electricity output and demonstrates that energy intensity improvements alone will make a significant contribution to carbon intensity forecasts. 


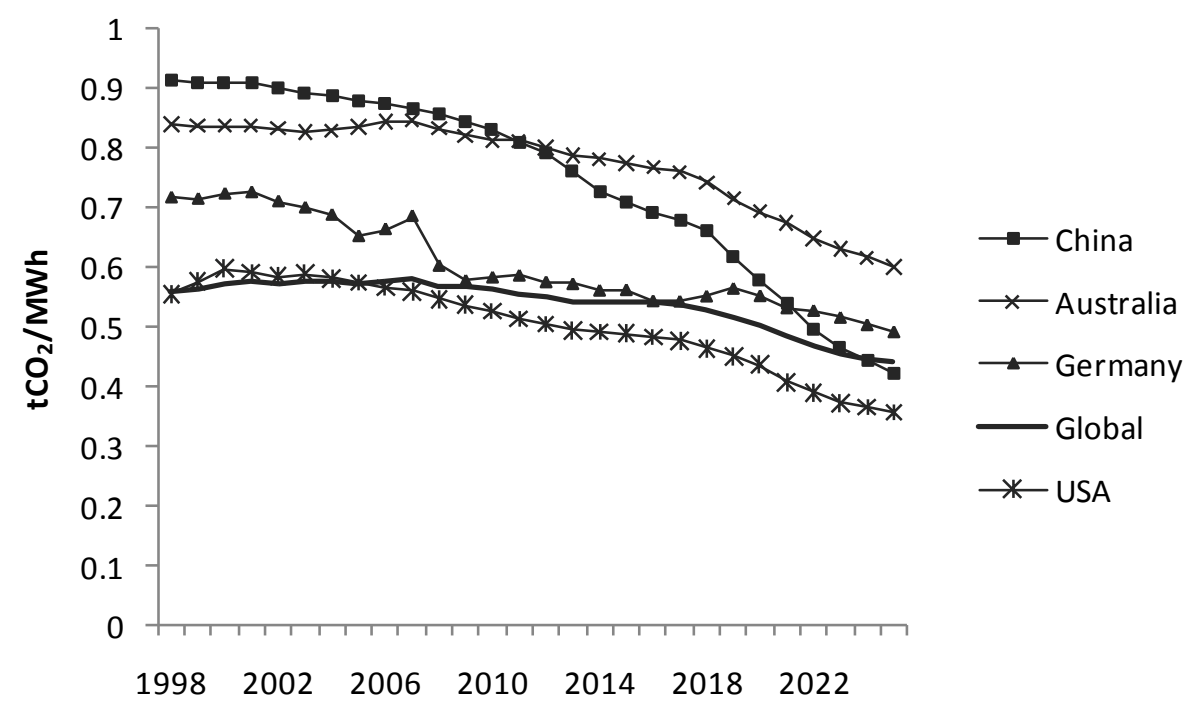

Figure 14: Carbon intensity per technology weighted with production per technology 2008-25.

\section{The Future Energy Mix}

The levelised cost model provides a number of outputs. Firstly power prices will be sensitive to both gas prices and emissions charges. The sensitivity to gas dominates other fuels such as coal and uranium since gas-fired generation is likely to become the swing power producer in OECD countries. Carbon charges also have a high impact on power prices and can cause regional differences in power prices. Power prices are not greatly sensitive to assumptions made for capital expenditure levels nor assumptions made for operating and maintenance costs.

Secondly large changes in projected generation capacity are unlikely, although the production mix is sensitive to the relative expected prices of coal and gas. Fluctuations in fuel, carbon charges and capital expenditure will have a limited impact on the 2025 power mix due to the high share of capacity that is under construction, planned or resulting from regulated mix targets. Changing input prices for either coal or gas will generally only drive substitution in the production mix between coal and gas.

Thirdly renewable energy sources will continue to grow but given the relative price levels of alternate sources of power they are unlikely to greatly alter the energy mix by 2025 . Humphreys and McLain (1998) and Awerbuch (2006) suggest employing portfolio theory principles for developing efficient portfolios of generating assets since the important measure is not the stand alone cost of a generating alternative but rather its contribution to overall portfolio cost relative to its contribution to overall portfolio risk. Lind (1986) and Awerbuch (2006) showed that under some circumstances while renewable energy generation may have higher expected busbar costs its addition to a generator's portfolio can serve to reduce overall portfolio costs without increasing risk. However for renewable energy to enhance the efficiency of a portfolio of generating assets the price volatility of input fuels such as coal and gas has to be sufficiently high while simultaneously the generation output of renewable energy must be below a certain threshold. Generators in OECD countries typically secure long term off-take agreements for input fuels at relatively stable prices and if they are unable to achieve price stability with a producer the presence of liquidly traded markets for coal and gas enables generators to hedge long term prices with third parties. Mitigating the volatility of fuel prices through price hedging alleviates the need 
to form a portfolio of fossil fuel and renewable energy technologies and the generator with the lowest average cost of production will be more efficient over the long term.

\section{CONCLUSIONS}

The above analysis outlines the relative levelised costs of alternative electricity generation in developed and developing countries to 2025. It is clear that coal, gas, nuclear, hydro and wind remain competitive over the long term for OECD countries with the inclusion of a price on carbon dioxide emissions. Non-OECD countries will continue to develop fossil fuel generation technologies due to the price advantage in the absence of an emissions price. Large-scale solar power remains very expensive even when high rates of technology advancement in the field are assumed. Other potential sources such as geothermal and tidal are decades from commercial-scale development and are unlikely to feature prominently in the global energy mix by 2025 .

In a world with carbon constraints and rising real fuel prices the levelised costs of generation will inevitably be higher than historical generation costs. Price convergence among all regions along with improved carbon intensity is expected under the assumptions used in the levelised cost model. Construction costs are expected to fall in the medium term for most technologies and especially newer technologies however the model did not explicitly consider supply chain bottlenecks for capital components required for renewable generation units. The imposition of a price on emissions in OECD countries will mobilise investment in newer technologies which are likely to incur significant learning premiums in their early deployment.

The levelised costs and the ranking of technologies are naturally sensitive to the discount rate and the projected prices of energy commodities. However the analysis shows that using reasonable projections of capital costs, fuel costs and a price on carbon-dioxide emissions, a relative cost of electricity output by generation type can be measured for developed and developing nations. 


\section{References}

Awerbuch, S. 1996, Capital budgeting, technological innovation and the emerging competitive environment of the electric power industry, Energy Policy 24 (2), 195-202.

Awerbuch, S. 2006, Portfolio-based electricity generation planning: Policy implications for renewable and energy security, Mitigation and Adaptation Strategies for Global Change 11, 693710.

Bar-Lev, D. and Katz, S. 1976, A portfolio approach to fossil fuel procurement in the electric utility industry, Journal of Finance 31(3), 933-947.

Barnett, D.W. 1994, Australia's coal industry: Fuel for growth, Energy Policy, 22 (4), 353-367.

California Energy Commission 2007, Comparative Costs of California Central Station Electricity Generation Technologies, Sacramento.

Commonwealth Scientific and Industrial Research Organisation (CSIRO) 2006, The Heat Is On: The Future of Energy in Australia, Canberra.

Humphreys, H.B. and McLain, K.T. 1998, Reducing the impacts of energy price volatility through dynamic portfolio selection, Energy Journal 19(3).

International Energy Agency (IEA) 2009, World Energy Outlook, Paris, OECD.

Lind, R.C. 1982, A primer on the major issues relating to the discount rate for evaluating national energy options, in C. Robert,Kenneth, A.L. et. al. (eds.), Discounting for Time and Risk in Energy Policy, DC: Resources for the Future, Johns Hopkins University Press.

Mott MacDonald Report 2010, UK Electricity Generation Costs Update, Brighton UK.

Nuclear Energy Institute 2008, The Cost of New Generating Capacity in Perspective, Washington DC.

West, J.M. 2011, Picking winners: Understanding the future cost of energy generation in Australia, forthcoming in JASSA: The Finsia Journal of Applied Finance. 